\title{
ANÁLISE DAS TENSÕES DE ÁGUA NO SOLO CULTIVADO COM MORANGUEIRO SOB PODA
}

\section{RAFAEL POMBO TEIXEIRA ${ }^{1 ;}$ GERALDO MAGELA PEREIRA ${ }^{2}$; ROVILSON JOSÉ DE SOUZA ${ }^{3}$; HENRIQUE HUDARI GARCIA ${ }^{4}$ E GUSTAVO BOSCO NOGUEIRA DA GAMA ${ }^{5}$.}

\footnotetext{
1 Departamento de Engenharia Rural, Universidade Estadual Paulista Julho de Mesquita Filho, Fazenda Lageado, rua José Barbosa de Barros, 1780, 18.610-307 - Botucatu, SP, Brasil, rafaelteixeira@fca.unesp.br

2 Departamento de Engenharia, Universidade Federal de Lavras, Campus Universitário Ufla, s/n, Inácio Valetim, 37200-000, Lavras, MG, Brasil, geraldop@deg.ufla.br

3 Departamento de Agricultura, Universidade Federal de Lavras, Campus Universitário Ufla, s/n, Inácio Valetim, 37200-000, Lavras, MG, Brasil, rovilson@dag.ufla.br

${ }^{4}$ Departamento de Engenharia, Universidade Federal de Lavras, Campus Universitário Ufla, s/n, Inácio Valetim, 37200-00, Lavras, MG, Brasil, henrique_garcia_9@hotmail.com.

${ }^{5}$ Departamento de Engenharia, Universidade Federal de Lavras, Campus Universitário Ufla, s/n, Inácio Valetim, 37200-00, Lavras, MG, Brasil, gustavobndg@gmail.com
}

\section{RESUMO}

Objetivou-se com este estudo avaliar o efeito de diferentes tensões de água no solo cultivado com morangueiro após poda drástica (segundo ciclo), irrigado por gotejamento. $\mathrm{O}$ experimento foi conduzido em canteiros no interior de uma casa de vegetação, localizada na área experimental do Departamento de Engenharia da Universidade Federal de Lavras (UFLA), no período de abril a dezembro de 2010. O delineamento experimental utilizado foi em blocos casualizados (DBC), com três repetições. Os tratamentos constituíram-se de seis tensões de água no solo, $15,25,35,45,55$ e $70 \mathrm{kPa}$. Concluiu-se que, para a obtenção dos maiores valores de massa fresca de frutos totais e comerciais por planta, número de frutos totais e comerciais por planta e produtividade total e comercial, deve-se irrigar no momento em que a tensão de água no solo estiver em torno de $15 \mathrm{kPa}$, à profundidade de $0,15 \mathrm{~m}$. A massa média de frutos comerciais e a massa fresca de frutos não comerciais por planta não foram afetadas pelas distintas tensões de água no solo.

PALAVRAS-CHAVE: Produção, Manejo da irrigação, Irrigação por gotejamento

\author{
TEIXEIRA, R. P.; PEREIRA, G. M.; DE SOUZA, R. J.; GARCIA, H. H.; DA GAMA, \\ G. B. N. \\ WATER TENSION ANALYSIS IN SOIL GROWN WITH STRAWBERRY UNDER \\ PRUNNING
}

\section{ABSTRACT}

Strawberry yield and quality was evaluated after drastic pruning (second cycle), under different soil water tensions, drip irrigation. The experiment was conducted on beds at a greenhouse, located at Engineering Department, Federal University of Lavras (UFLA), from April to December of 2010. An experimental design was in randomized blocks with three replicates. The treatments were composed of six different soil water tension, 15, 25, 35, 45, 55 e $70 \mathrm{kPa}$. 
Results obtained allowed to verify that to higher values of: total and commercial fresh weight of fruits per plant, total and commercial number fruits per plant and total and commercial yield, it is necessary to irrigate when soil water tension gets approximately to $15 \mathrm{kPa}$, at $0.15 \mathrm{~m}$ deep. Commercial average fruit mass and noncommercial fresh weight of fruits per plant, were not reduced under different soil water tensions applied.

KEYWORDS: Pruning strawberry. Irrigation management. Drip irrigation.

\section{INTRODUÇÃO}

O estado de Minas Gerais, maior produtor nacional de morango, tem na região de Pouso Alegre, situada no Sul do estado e distante $160 \mathrm{~km}$ da cidade de Lavras, o principal polo de produção de morangos do país. Entretanto, considerando apenas as cidades de Pouso Alegre, Bom Repouso, Cambuí, Estiva, Espírito Santo do Dourado e Tocos do Mogi, a área total cultivada é de 1.200 ha e possui cerca de 3.387 produtores e área média de 0,35 ha por produtor (CARVALHO, 2006).

No Brasil, o avanço crescente da pesquisa e o emprego de alta tecnologia no cultivo do morangueiro têm permitido produtividades de até 80 t.ha $^{-1}$ em regiões com condições edafoclimáticas propícias. A alta rentabilidade econômica da cultura (cerca de $224 \%$ ) em comparação com outras culturas como milho (72\%) e soja (2\%), tem despertado o interesse dos agricultores. A cultura desempenha também função social importante, devido à grande absorção de mão de obra e ao fato de ser conduzida, principalmente, em pequenas propriedades de base familiar, proporcionando uma melhoria sensível na geração de empregos e renda e consequentemente, na qualidade de vida das famílias produtoras (DIAS et al., 2007).

A Aromas é uma cultivar neutra obtida pela Universidade da Califórnia, em 1997, com hábito de crescimento ereto e produtividade obtida em ambiente protegido ao redor de 880 g.planta ${ }^{-1}$ (CALVETE et al., 2007). Os frutos são de tamanho grandes, coloração vermelhaescura, sabor agradável e qualidade excelente para o consumo in natura e para industrialização. A cultivar Aromas é considerada mais resistente do que a cultivar Diamante em relação às variações nas condições ambientais (SANHUEZA, 2005).

A deficiência hídrica afeta a expansão da área foliar que pode chegar à metade com redução de apenas $25 \%$ da água necessária a cultura. Isto mostra a sensibilidade dessa cultura às condições hídricas do solo (EL-FARHAN; PRITTS, 2002).

Particularmente, na região do Sul do Estado de Minas Gerais, estudos sobre a produção do morangueiro irrigado por gotejamento ainda são escassos, principalmente quanto ao aspecto do manejo adequado da irrigação, ou seja, o momento oportuno de irrigar e a quantidade de água a ser aplicada (COSTA, 2011).

Diante do exposto, objetivou-se com este estudo avaliar o efeito de diferentes tensões de água no solo sobre a produção e qualidade de frutos do morangueiro após a poda drástica (segundo ciclo), sob diferentes tensões de água no solo, irrigado por gotejamento nas condições edafoclimáticas do sul de Minas Gerais.

\section{MATERIAL E MÉTODOS}

O experimento foi conduzido em casa de vegetação, modelo arco, construída na área experimental do Departamento de Engenharia da Universidade Federal de Lavras (UFLA). A 
UFLA situa-se no município de Lavras, região sul do Estado de Minas Gerais, tendo como referência as seguintes coordenadas geográficas: latitude $21^{\circ} 14^{\prime} \mathrm{S}$, longitude $45^{\circ} 00^{\prime} \mathrm{W}$ Gr. e $918 \mathrm{~m}$ de altitude média.

O experimento teve início com a poda drástica das plantas realizada em 21/04/2010 e término com as colheitas no dia 09/12/2010.

No preparo inicial, foi efetuada a poda drástica da parte aérea das plantas (Figura 1), deixando apenas algumas folhas para o seu desenvolvimento, aproveitando assim, o segundo ciclo e economizando mão de obra (preparo do solo e plantio), mudas, "mulching" e outros gastos com a implantação de uma nova área de produção.

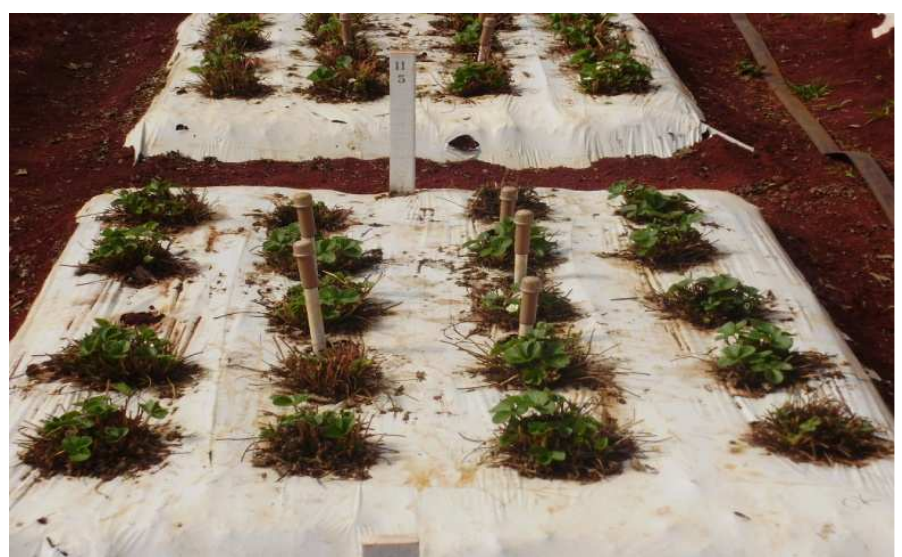

Figura 1. Visão de uma parcela experimental após efetuar a poda drástica do morangueiro.

De acordo com a classificação climática de Köppen (DANTAS; CARVALHO; FERREIRA, 2007), a região de Lavras apresenta um clima Cwa, ou seja, clima temperado chuvoso (mesotérmico), com inverno seco e verão chuvoso, subtropical.

O solo classificado originalmente como um Latossolo Vermelho Distroférrico (EMPRESA BRASILEIRA DE PESQUISA AGROPECUÁRIA - EMBRAPA, 1999), foi coletado na camada de 0 a $0,30 \mathrm{~m}$ de profundidade. As análises físicas e químicas foram realizadas em uma amostra composta representativa, enviada aos Laboratórios de Física e de Fertilidade do Solo do Departamento de Ciência do Solo da UFLA, respectivamente.

Como o presente experimento aproveitou o segundo ciclo de cultivo do morangueiro, a adubação de plantio foi realizada como está descrito em Costa (2011).

Para a determinação da curva de retenção da água no solo, amostras de solo foram coletadas à profundidade de 0,15-0,30 m e levadas ao Laboratório de Física do Solo para análise.

Amostras de solo com estrutura deformada (terra fina seca ao ar) foram colocadas em cilindros de PVC, e depois de saturadas foram levadas para uma bancada dotada de funil de Haines para determinação dos pontos de menor tensão $(2,4,6$ e $10 \mathrm{kPa})$, bem como para Câmara de Pressão de Richards para os pontos de maior tensão $(33,100,500$ e $1500 \mathrm{kPa})$. Esse procedimento foi realizado para a caracterização físico-hídrica da camada de $0,15-0,30$ $\mathrm{m}$ do solo.

Com a utilização do programa computacional SWRC, desenvolvido por Dourado Neto et al. (1990), foi gerada a equação, ajustada segundo modelo proposto por van Genuchten (1980), que descreve o comportamento da umidade do solo em função da tensão de água no solo (Equação 1). Com base nessa equação e nos valores observados, foi gerada a curva de retenção de água no solo para a camada em estudo (Figura 2). 


$$
\theta=0,217+\frac{0,304}{\left[1+(0,2325 \cdot \psi)^{1,7786}\right]^{0,4378}}
$$

em que:

$\theta$ - umidade do solo com base em volume $\left(\mathrm{cm}^{3} \cdot \mathrm{cm}^{-3}\right)$; e

$\Psi$ - tensão de água no solo $(\mathrm{kPa})$.

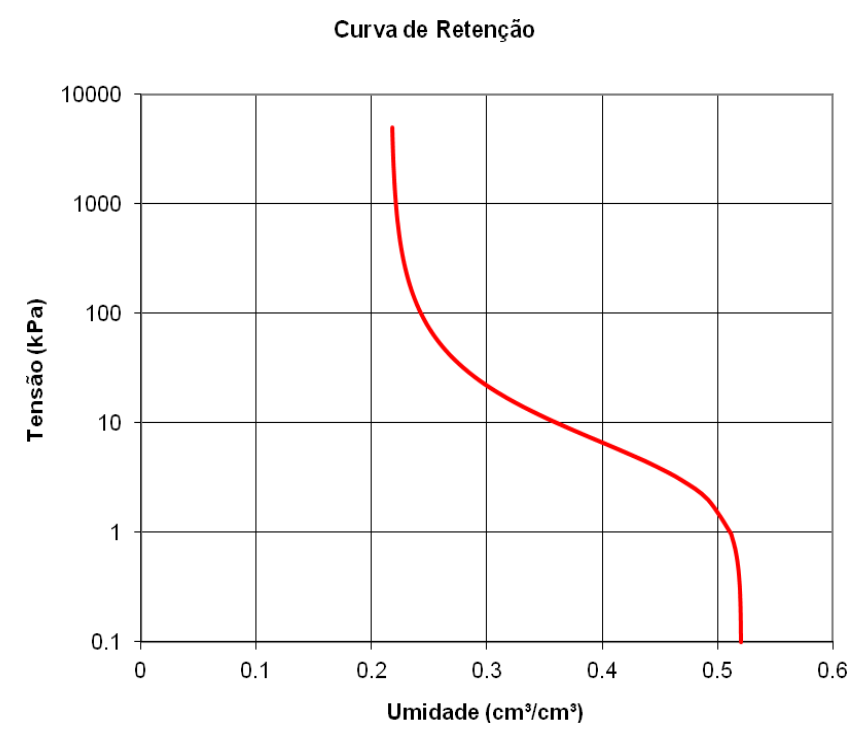

Figura 2. Curva de retenção da água no solo, gerada utilizando-se o modelo proposto por van Genuchten (1980).

De acordo com Carvalho, Sampaio e Silva (1996) para o solo deste experimento, a tensão de $10 \mathrm{kPa}$ é a recomendada para determinar a umidade do solo correspondente à capacidade de campo. Portanto, utilizando-se a Equação 1, o valor da umidade na capacidade de campo foi de $0,361 \mathrm{~cm}^{3} \cdot \mathrm{cm}^{-3}$.

Foi empregado o delineamento em blocos casualizados (DBC), com seis tratamentos e três repetições. Os tratamentos constituíram-se de seis tensões de água no solo $(15,25,35,45$, 55 e $70 \mathrm{kPa}$ ) como indicativo do momento de irrigar (tensão crítica).

A diferenciação dos tratamentos com irrigação foi realizada durante as fases de florescimento e frutificação. Na fase vegetativa, logo após a poda drástica das mudas, todos os tratamentos foram irrigados igualmente, quando os tensiômetros de decisão indicavam uma tensão de água no solo de $15 \mathrm{kPa}$ (procurando manter a umidade do solo próximo à capacidade de campo), visando o estabelecimento da cultura e a uniformização da umidade do solo nas parcelas.

Para monitorar o estado de energia da água no solo, foi instalada uma bateria com cinco tensiômetros (três a $0,15 \mathrm{~m}$ de profundidade para o monitoramento da irrigação, ou seja, tensiômetros de decisão, e dois a $0,30 \mathrm{~m}$ de profundidade para verificar a ocorrência de percolação), sorteada entre as parcelas de cada tratamento, adotando-se o critério de reiniciar as irrigações quando pelo menos dois dos tensiômetros de decisão atingiam a tensão crítica. As leituras nos tensiômetros foram realizadas utilizando-se um tensímetro digital de punção. Os tensiômetros foram instalados nas linhas internas de plantas e ficaram distanciados de 0,30 m entre si em cada bateria (Figura 3 e 6).

Cada parcela experimental (canteiro) teve a dimensão de 1,20 m de largura por 1,50 m de comprimento $\left(1,80 \mathrm{~m}^{2}\right)$. Foram utilizadas quatro linhas de plantas espaçadas de $0,30 \mathrm{~m}$ 
entre si e $0,30 \mathrm{~m}$ entre plantas, totalizando 20 plantas por parcela. Foi considerada parcela útil, as duas linhas centrais de plantas, sendo descartada nestas linhas, uma planta no início e uma no final (bordadura), resultando em uma parcela útil com seis plantas (Figura 3).
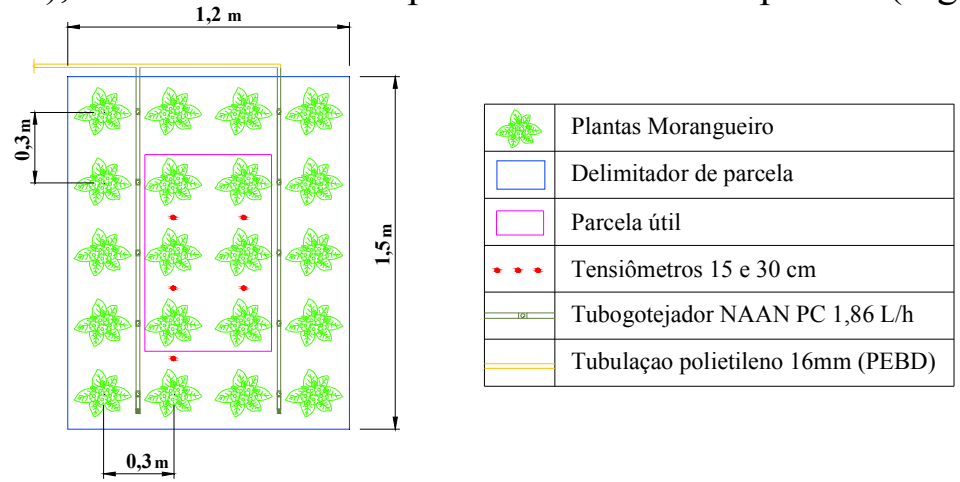

Figura 3. Esquema de uma parcela experimental com o sistema de irrigação e os tensiômetros instalados.

Foi utilizado para a diferenciação dos tratamentos, um sistema de irrigação por gotejamento, sendo os emissores autocompensantes do tipo in-line, ou seja, emissores inseridos no tubo, durante o processo de extrusão, modelo NAAN PC com vazão nominal de 1,6 L.h ${ }^{-1}$ e distanciados a $0,30 \mathrm{~m}$ entre si. O tubo gotejador (DN $16 \mathrm{~mm}$ ) ficou posicionado na parcela, de forma a atender duas fileiras de plantas, trabalhando com pressão de serviço de $140 \mathrm{kPa}$, que era regulada por meio de uma válvula reguladora de pressão, inserida no cabeçal de controle, antes das válvulas de comando elétrico (solenoides). Foi utilizada uma válvula solenoide para cada tratamento; tais válvulas eram acionadas por meio de um Controlador Lógico Programável (RAIN BIRD), previamente programado, em cada irrigação, para funcionar o tempo necessário visando repor a lâmina d'água acusada indiretamente pelos tensiômetros.

Buscava-se, em todas as irrigações, elevar à capacidade de campo a umidade correspondente à tensão verificada no momento de irrigar. $O$ cálculo do tempo de funcionamento do sistema de irrigação em cada tratamento foi feito com base nos tensiômetros instalados na profundidade de $0,15 \mathrm{~m}$. Estes tensiômetros funcionavam como sensores de decisão, ou seja, de posse dos valores de suas respectivas leituras eram tomadas as decisões para irrigar ou não os tratamentos. Já os tensiômetros, instalados a $0,30 \mathrm{~m}$ de profundidade, funcionavam como sensores de controle da lâmina aplicada em cada tratamento. De posse dessas leituras, era possível estabelecer uma relação direta entre a lâmina aplicada e os valores de tensão observados, evitando-se assim, o excesso no fornecimento de água e consequentemente, percolação e lixiviação de nutrientes no perfil do solo.

Foram realizados testes para determinar a vazão média do gotejador e o coeficiente de uniformidade de distribuição de água (CUD), do sistema de irrigação no primeiro ciclo de cultivo do morangueiro conforme descrito em Costa (2011).

Neste trabalho foi utilizada a cultivar de morango "Aromas". As plantas foram submetidas à poda drástica da parte aérea, para ocorrer a rebrota e assim aproveitando o segundo ciclo de cultivo.

Todos os canteiros receberam cobertura plástica (operação realizada no primeiro ciclo), denominada mulching. Para isto foi utilizado filme plástico com dupla face, sendo a parte superior branca e a parte inferior preta, com espessura de 25 micra, aditivado com tratamento anti UV e largura de $1,50 \mathrm{~m}$. 
Desde a poda das plantas, ocorrida no dia 21 de abril de 2010, até o início da diferenciação dos tratamentos no dia 25 de julho de 2010, foram realizadas irrigações por gotejamento em todos os seis tratamentos, visando manter a umidade do solo próximo à capacidade de campo $(15 \mathrm{kPa})$, totalizando uma lâmina de $185,9 \mathrm{~mm}$ por tratamento. Este procedimento teve como objetivo proporcionar melhor condição para rebrota, e permitir a uniformização do desenvolvimento das plantas.

Toda a adubação de cobertura foi feita via fertirrigação seguindo as recomendações da 5ª aproximação (GOMES; SILVA; FAQUIN, 1999) e do Informe Agropecuário (PACHECO et al., 2007). Os adubos utilizados foram cloreto de potássio e ureia. As adubações de cobertura forneceram durante todo o ciclo da cultura as quantidades, em kg.ha ${ }^{-1}$, de $266 \mathrm{de} \mathrm{K}$ e 230 de $\mathrm{N}$.

Foi utilizada para a realização das fertirrigações uma bomba de injeção de fertilizante, ou bomba dosificadora hidráulica modelo TMB WP - 10, com capacidade máxima de injeção de 60 L.h ${ }^{-1}$ de solução.

As fertirrigações foram distribuídas durante o ciclo, em sete aplicações, buscando-se adequar a quantidade de nutrientes fornecida de forma equilibrada e balanceada, de acordo com as necessidades nutricionais da cultura.

Com o objetivo de prevenir sintomas de deficiências nutricionais, que poderiam aparecer durante desenvolvimento da cultura, foram feitas aplicações do fertilizante foliar Aminon 25 a cada 15 dias, durante todo o ciclo. O fertilizante foliar Aminon 25 possui em sua fórmula as seguintes concentrações de nutrientes: $11 \%$ de $\mathrm{N}, 1 \%$ de $\mathrm{K}_{2} \mathrm{O}$ e $6 \%$ de $\mathrm{C}$ orgânico.

$\mathrm{O}$ controle fitossanitário foi feito com base em avaliações visuais, realizando inspeções periódicas, a fim de se detectar a presença de pragas e a ocorrência de doenças durante o cultivo.

As aplicações dos defensivos foram realizadas na medida em que se detectava a presença de doenças e pragas.

Para as análises da produção as colheitas começaram a ser realizadas no dia 14 de agosto de 2010, quando os frutos começaram a apresentar pelo menos $75 \%$ de coloração vermelha. A partir daí, as colheitas foram realizadas semanalmente, as quartas-feiras, até o dia 09 de dezembro de 2010.

As avaliações foram feitas, imediatamente, após as colheitas das parcelas úteis, sendo todas as repetições colhidas e avaliadas no mesmo dia.

Para massa fresca total de frutos por planta foram realizadas as pesagens dos frutos da parcela útil, em balança digital com precisão de $1 \mathrm{~g}$, e a massa fresca total de frutos foi dividida pelo número de plantas da parcela útil, sendo os resultados expressos em gramas por planta.

A massa fresca de frutos comerciais por planta foi obtida, dividindo-se a massa fresca de frutos comerciais pelo número de plantas da parcela útil.

Foram considerados comerciais, os frutos perfeitos e com massa mínima de seis gramas (DUARTE FILHO; ANTUNES; PÁDUA, 2007). Os resultados foram expressos em gramas por planta.

A massa fresca de frutos não comerciais por planta foi determinada, dividindo-se a massa fresca de frutos não comerciais pelo número de plantas da parcela útil. Foram considerados não comerciais, os frutos com podridões, imperfeições físicas e ataques de fungos, insetos e pássaros (DUARTE FILHO; ANTUNES; PÁDUA, 2007). Os resultados foram expressos em gramas por planta. 
Para o número total de frutos por planta os frutos derivados da parcela útil foram contados e o número total de frutos foi dividido pelo número de plantas da parcela útil, sendo os resultados expressos em frutos por planta.

O número de frutos comerciais por planta foi determinado, dividindo-se o número de frutos comerciais pelo número de plantas da parcela útil, sendo os resultados expressos em frutos por planta.

Calculou-se a massa média de frutos comerciais pela divisão entre a massa fresca de frutos comerciais por planta e o número de frutos comerciais por planta. Os resultados foram expressos em gramas por fruto.

Com base nas dimensões dos canteiros e no espaçamento entre as plantas $(0,30 \times 0,30$ $\mathrm{m})$, estimou-se uma população de 89.000 plantas por hectare, considerando que $20 \%$ da área são destinados à circulação entre os canteiros. A partir dos valores médios de massa fresca total de frutos por planta e da população de plantas por hectare, foi calculada a produtividade total de frutos. Os resultados foram expressos em toneladas por hectare.

Com os valores médios de massa fresca de frutos comerciais por planta e população de plantas por hectare, foi calculada a produtividade comercial de frutos. Os resultados foram expressos em toneladas por hectare.

Os dados amostrados foram submetidos à análise de variância, com a realização do teste $\mathrm{F}$, e análise de regressão polinomial a 5\% e 1\% de probabilidade (GOMES, 2000).

As análises foram efetuadas, utilizando-se o programa computacional Sisvar para Windows, versão 4.0, para análises estatísticas (FERREIRA, 2000).

\section{RESULTADOS E DISCUSSÃO}

Encontrou-se uma vazão média dos gotejadores de 1,86 L.h ${ }^{-1}$. O coeficiente de uniformidade de distribuição de água (CUD) encontrado foi de $99 \%$, significando que a água foi, uniformemente, distribuída nas parcelas, em qualquer nível de irrigação, não se constituindo em uma fonte de variação adicional ao ensaio.

Calculou-se, também, o coeficiente de variação total de vazão $(\mathrm{CVt})$. $\mathrm{O}$ valor encontrado para o mesmo foi de 0,007 , indicando uma excelente uniformidade de vazão nos tratamentos, de acordo com Cabello (1996).

Demonstra-se na Tabela 1, as lâminas de água aplicadas, nas diferentes tensões de água no solo analisadas, no período de condução do experimento, bem como o turno de rega e o número de irrigações.

Tabela 1. Tensões de água no solo estabelecidas, lâminas aplicadas antes da diferenciação dos tratamentos (Inicial), e após a diferenciação dos tratamentos (Irrigação), lâmina total (Total), média da lâmina aplicada por irrigação (mpi), turno de rega (TR) e número de irrigações (NI).

\begin{tabular}{|c|c|c|c|c|c|c|}
\hline \multirow{2}{*}{$\begin{array}{c}\text { Tensão } \\
\text { (kPa) }\end{array}$} & \multicolumn{4}{|c|}{ Lâmina (mm) } & \multirow{2}{*}{$\begin{array}{c}\text { TR } \\
\text { (dia) }\end{array}$} & \multirow{2}{*}{ NI (ud) } \\
\hline & Inicial & Irrigação & Total & mpi & & \\
\hline 15 & 185,9 & 692,2 & 878,1 & 10,3 & 2,0 & 67 \\
\hline 25 & 185,9 & 616,7 & 802,6 & 20,5 & 4,5 & 30 \\
\hline 35 & 185,9 & 615,6 & 801,5 & 25,6 & 5,7 & 24 \\
\hline 45 & 185,9 & 545,9 & 731,8 & 28,7 & 7,2 & 19 \\
\hline 55 & 185,9 & 462,2 & 648,1 & 30,8 & 9,1 & 15 \\
\hline 70 & 185,9 & 230,5 & 416,4 & 32,9 & 19,5 & 7 \\
\hline
\end{tabular}


Quanto menor as tensões para que fossem reiniciadas as irrigações, por exemplo, 15 e $25 \mathrm{kPa}$, mais frequentes foram as mesmas (TR iguais a 2,0 e 4,5 dias, respectivamente) e maiores foram as lâminas aplicadas (692,2 e 616,7 mm, respectivamente), sendo os valores de tensões de água no solo mantidos dentro de uma faixa mais estreita (menores "picos") e consequentemente, a umidade do solo permaneceu próxima à capacidade de campo, ao longo de todo o ciclo da cultura. $\mathrm{O}$ tratamento que apresentou a maior lâmina total aplicada $(878,1$ $\mathrm{mm}$ ) foi o de $15 \mathrm{kPa}$.

$\mathrm{Na}$ Figura 4 estão representadas as tensões médias registradas pelos tensiômetros, instalados nas profundidades de 0,15 e $0,30 \mathrm{~m}$, no tratamento de $45 \mathrm{kPa}$ para exemplificar o comportamento das tensões durante o ciclo. Nessa figura, pode-se visualizar o número de irrigações realizadas durante o período da diferenciação dos tratamentos. Observa-se também, que na profundidade de $15 \mathrm{~cm}$, a umidade do solo apresentou maior amplitude de variação.
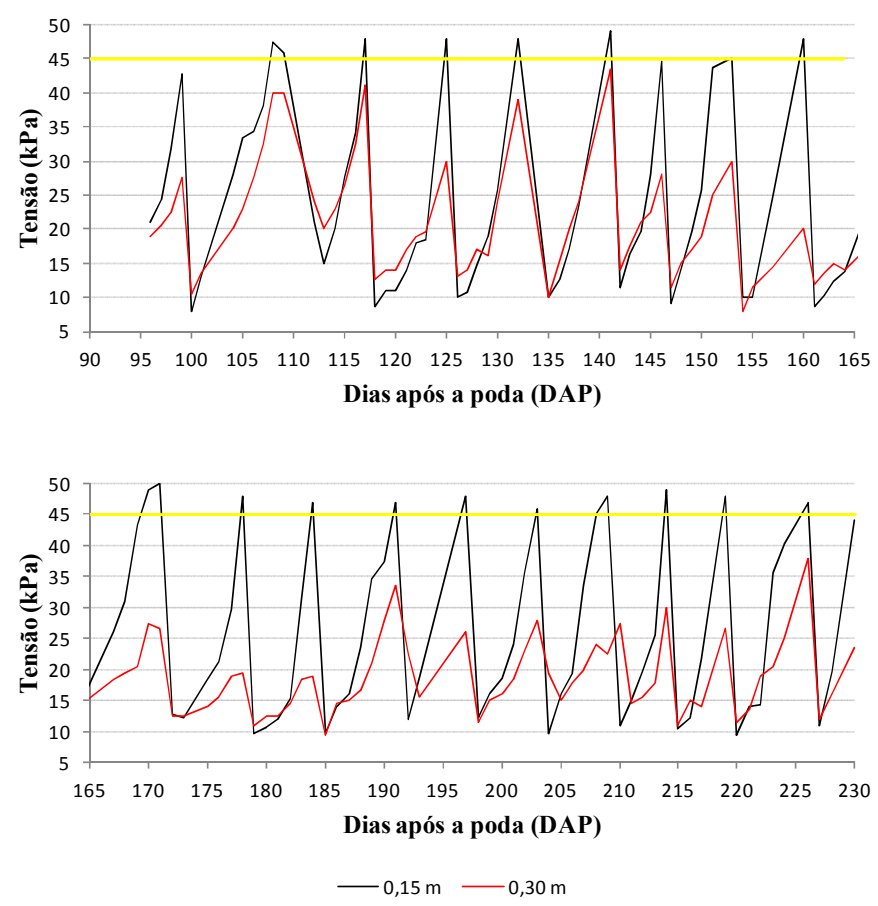

Figura 4. Variação das tensões no tratamento de $45 \mathrm{kPa}$, nas profundidades de 0,15 e $0,30 \mathrm{~m}$.

De acordo com a análise de variância (Tabela 2), verifica-se efeito significativo a 1\% de probabilidade, para a massa fresca total de frutos por planta, com relação ao fator tensões de água no solo.

Tabela 1. Resumo das análises de variância e de regressão para massa fresca total de frutos (MFTF) por planta, sob diferentes tensões da água no solo.

\begin{tabular}{ccc}
\hline \multirow{2}{*}{ Fontes de variação } & \multirow{2}{*}{ G. L. } & Q. M. \\
\cline { 3 - 3 } & 2 & MFTF (g.planta \\
Bloco & $19445,54^{* * *}$ \\
Tensões & 5 & $52028,42^{* *}$ \\
Resíduo & 10 & 1736,03 \\
\hline Média Geral & - & 371,61 \\
C.V. $(\%)$ & - & 11,21 \\
\hline Linear & 1 & $255418,55^{* *}$ \\
Quadrática & 1 & $4396,71^{\text {ns }}$ \\
Desvios & 3 & $108,94^{\text {ns }}$ \\
\hline Nota $:^{\text {ns }}$ - não significativo pelo teste F e ${ }^{* *}-$ significativos a $1 \%$ de probabilidade.
\end{tabular}


Pereira (2009), comparando a produtividade de diferentes cultivares do morangueiro, em diferentes épocas de plantio, obteve os seguintes resultados da produtividade total de frutos para cultivar Aromas de 650,43 e 298,18 g.planta $^{-1}$ nos plantios dos meses de maio e junho, respectivamente. Este experimento também foi realizado na região do Sul de Minas, em condições de clima semelhantes a este estudo. Os resultados mostram a superioridade na produção da cultivar Aromas, quando plantada no mês de maio, em comparação ao plantio no mês junho, sendo esta mais adaptada às características climáticas da região nesta época.

A massa fresca total de frutos por planta foi bastante influenciada pelas tensões de água no solo. $\mathrm{O}$ resultado de massa fresca total de frutos por planta mostrou resposta linear inversa, com nível de significância de 1\% (Tabela 2), indicando haver um decréscimo da massa fresca total de frutos por planta na medida em que se aumentaram as tensões de água no solo. Nota-se que, $98,18 \%$ das variações ocorridas na massa fresca total de frutos por planta, em função das tensões são explicadas pela regressão linear inversa (Figura 5). O valor máximo para a massa fresca total de frutos por planta ocorreu à tensão de $15 \mathrm{kPa}$, considerando o intervalo estudado (15 a $70 \mathrm{kPa})$, resultando em uma produção para esta característica de 538,29 g.planta ${ }^{-1}$.

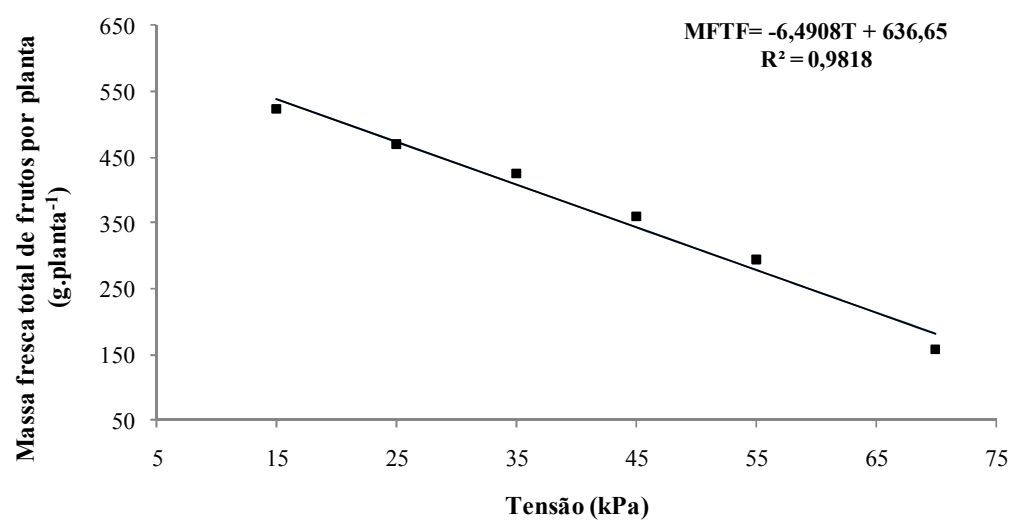

Figura 5. Massa fresca total de frutos (MFTF) por planta de morangueiro, em função das diferentes tensões de água no solo.

De acordo com a equação representada na Figura 5, o aumento da tensão de água no solo, em uma unidade $(\mathrm{kPa})$, implicará em uma diminuição de 6,49 g.planta ${ }^{-1}$ na massa fresca total de frutos por planta, considerando o intervalo estudado. Isto quer dizer que, neste intervalo, quanto menor o turno de rega, maior é a massa fresca total de frutos por planta, pois a água é aplicada em pequenas intensidades, porém com alta frequência, de modo a manter a umidade do solo na zona radicular próxima à capacidade de campo.

De acordo com a análise de variância (Tabela 3), para a massa fresca de frutos comerciais por planta, verifica-se efeito significativo a $1 \%$ de probabilidade com relação ao fator tensões da água no solo. 
Tabela 2. Resumo das análises de variância e de regressão para massa fresca de frutos comerciais (MFFC) por planta, sob diferentes tensões de água no solo.

\begin{tabular}{ccc}
\hline \multirow{2}{*}{ Fontes de variação } & \multirow{2}{*}{ G. L. } & Q. M. \\
\cline { 3 - 3 } & 2 & \left.${\text { MFFC }\left(\mathbf{g} \cdot \text { planta }^{-1}\right)}^{* *}\right)$ \\
Bloco & 5 & $21110,67^{* *}$ \\
Rensões & 10 & $56521,07^{* *}$ \\
Resíduo & - & 1741,40 \\
\hline Média Geral & - & 323,40 \\
C.V. $(\%)$ & 1 & 12,90 \\
\hline Linear & 1 & $279027,05^{* *}$ \\
Quadrática & 3 & $2629,68^{\text {ns }}$ \\
Desvios & $316,22^{\text {ns }}$ \\
\hline Nota: ${ }^{\text {ns }}$ - não significativo pelo teste F e ${ }^{* *}-$ significativo a $1 \%$ de probabilidade.
\end{tabular}

No caso da massa fresca de frutos comerciais por planta, as variações ocorridas podem ser explicadas pela regressão linear inversa, a 1\% de probabilidade (Tabela 3 ). O valor médio encontrado para massa fresca de frutos comerciais por planta foi de 323,40 g.planta ${ }^{-1}$.

Nota-se, pela Figura 6, que houve um acréscimo na massa fresca de frutos comerciais por planta, à medida que se diminuíram as tensões de água no solo, sendo obtido o valor máximo à tensão de $15 \mathrm{kPa}$, resultando em uma produção de 498,66 g.planta ${ }^{-1}$.

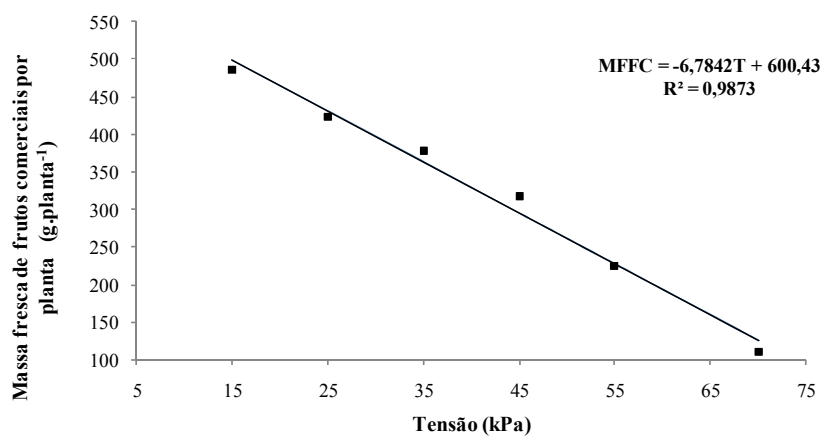

Figura 6. Massa fresca de frutos comerciais (MFFC) por planta de morangueiro, em função das diferentes tensões da água no solo.

Observa-se que $98,73 \%$ das variações, ocorridas na massa fresca de frutos comerciais por planta, em função das tensões, são explicadas pela regressão linear (Figura 6).

Segundo Pires et al. (2007), na condição de cultivo protegido, o uso do filme plástico transparente e a manutenção do teor de água do solo a tensões entre 10 e $35 \mathrm{kPa}$ favoreceram a produção total de frutos comerciais e seus componentes (número e massa média dos frutos).

A tensão de água no solo de $15 \mathrm{kPa}$ proporcionou o maior valor para massa fresca de frutos comerciais por planta, atingindo 498,66 g.planta ${ }^{-1}$, com média geral de 323,40 g.planta ${ }^{-}$ 1 , apresentando assim, valor maior em comparação ao experimento realizado no primeiro ciclo, cuja média geral foi de 115,84 g.planta ${ }^{-1}$ (COSTA, 2011). Isso se deve, provavelmente, a época de início do estudo, mês de abril, e também ao rápido desenvolvimento das plantas devido à realização da poda drástica.

Pereira (2009) avaliando a produtividade de cultivares de morangueiros em diferentes épocas de plantio na região sul do estado de Minas Gerais, conduzido no município de Bom Repouso, utilizando-se quatros cultivares (Aromas, Camarosa, Festival e Oso Grande) e 
quatro épocas de plantio (maio, junho, julho e agosto), observou que, à medida que se atrasa o plantio, há uma queda gradativa na produção em todas as cultivares.

De acordo com a análise de variância (Tabela 4), para a massa fresca de frutos não comerciais por planta, verifica-se que não houve diferença significativa com relação ao fator tensões de água no solo.

Tabela 3. Resumo da análise de variância para massa fresca de frutos não comerciais (MFFNC) por planta, sob diferentes tensões de água no solo.

\begin{tabular}{ccc}
\hline \multirow{2}{*}{ Fontes de variação } & \multirow{2}{*}{ G. L. } & Q. M. \\
\cline { 3 - 3 } & 2 & MFFNC (g.planta $^{\mathbf{- 1}}$ ) \\
\hline Bloco & 5 & $36,56^{\mathrm{ns}}$ \\
Tensões & 10 & $408,89^{\mathrm{ns}}$ \\
Resíduo & - & 195,14 \\
\hline Média Geral & - & 48,63 \\
C.V. (\%) & & 28,72 \\
\hline
\end{tabular}

Nota: ${ }^{\text {ns }}$ - não significativo pelo teste $\mathrm{F}$.

A proporção da massa fresca de frutos não comerciais em relação à massa fresca total de frutos foi de $13,08 \%$.

$\mathrm{Na}$ análise de variância (Tabela 5) foi verificado que houve diferença significativa a $1 \%$ de probabilidade, em relação ao fator tensões da água no solo, quanto ao número de frutos total por planta.

Tabela 4. Resumo das análises de variância e de regressão para número total de frutos (NTF) por planta, sob diferentes tensões de água no solo.

\begin{tabular}{ccc}
\hline \multirow{2}{*}{ Fontes de variação } & \multirow{2}{*}{ G. L. } & Q. M. \\
\cline { 3 - 3 } & & NFT (frutos.planta ${ }^{-1}$ ) \\
Bloco & 5 & $123,60^{* *}$ \\
Tensões & 10 & $314,82^{* *}$ \\
Resíduo & - & 20,20 \\
\hline Média Geral & - & 41,76 \\
C.V. (\%) & 1 & 10,76 \\
\hline Linear & 1 & $1474,57^{* *}$ \\
Quadrática & 3 & $75,08^{\text {ns }}$ \\
Desvios & $8,14^{\text {ns }}$ \\
Nota: ${ }^{\text {ns }}$ - não significativo pelo teste F, ${ }^{*} \mathrm{e}^{* *}-$ significativos a 5 e $1 \%$ de probabilidade, \\
respectivamente.
\end{tabular}

As variações ocorridas no número total de frutos por planta, em função das tensões avaliadas, podem ser explicadas pela regressão linear inversa, a 1\% de probabilidade (Quadro $5)$.

Nota-se, pela Figura 7, que houve um decréscimo no número total de frutos por planta, à medida que se aumentaram as tensões da água no solo. Observa-se que $93,68 \%$ das variações, ocorridas no número de frutos total por planta, em função das tensões, são explicadas pela regressão linear.

Para a cultivar Chandler, Serrano et al. (1992) verificaram que a produção máxima foi obtida quando a tensão de água no solo atingiu $10 \mathrm{kPa}$; na faixa de 30 a $70 \mathrm{kPa}$, o decréscimo 
na área foliar levou a redução na taxa de assimilação total e na produção. Esta decorre da diminuição no peso médio e no número de frutos, conforme as conclusões do autor.

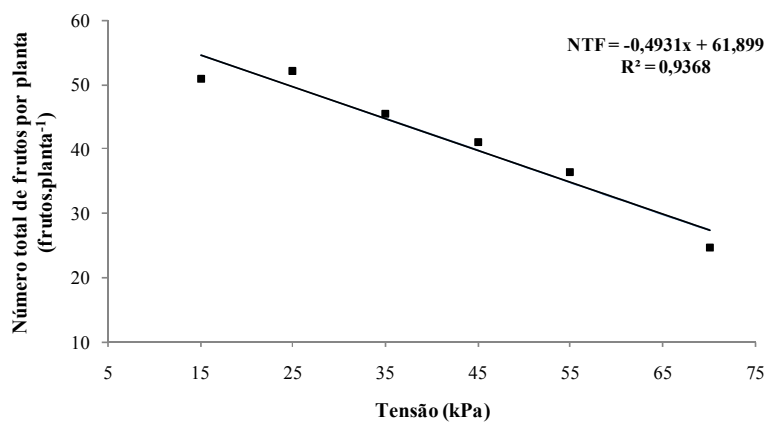

Figura 7. Número total de frutos (NTF) por planta de morangueiro, em função das diferentes tensões da água no solo.

O maior valor encontrado para o número total de frutos por planta ocorreu à tensão de $15 \mathrm{kPa}$, atingindo 54,50 frutos por planta. A média geral foi de 41,76 frutos por planta, este valor encontrado é maior comparado ao valor obtido no primeiro ciclo, cuja média geral foi de 17,53 frutos totais por planta (COSTA, 2011). Isso se deve, provavelmente, a época de início do estudo, mês de abril, e também ao rápido desenvolvimento das plantas devido à realização da poda drástica.

$\mathrm{Na}$ análise de variância (Tabela 6), verifica-se que houve diferença significativa a 1\% de probabilidade, em relação ao fator tensões de água no solo, quanto ao número de frutos comerciais por planta.

Tabela 5. Resumo das análises de variância e de regressão para número de frutos comerciais (NFC) por planta, sob diferentes tensões da água no solo.

\begin{tabular}{ccc}
\hline \multirow{2}{*}{ Fontes de variação } & \multirow{2}{*}{ G. L. } & Q. M. \\
\cline { 3 - 3 } & 2 & NFC (frutos.planta ${ }^{-1}$ ) \\
Bloco & 5 & $165,48^{* *}$ \\
Tensões & 10 & $433,88^{* *}$ \\
Resíduo & - & 7,51 \\
\hline Média Geral & - & 31,96 \\
C.V. $(\%)$ & 1 & 8,57 \\
\hline Linear & 1 & $2115,13^{* *}$ \\
Quadrática & 3 & $34,88^{\mathrm{ns}}$ \\
Desvios & $6,46^{\mathrm{ns}}$ \\
\hline Nota: $^{\text {ns }}$ - não significativo pelo teste $\mathrm{F} \mathrm{e}^{* *}-$ significativo a $1 \%$ de probabilidade.
\end{tabular}

As variações ocorridas no número de frutos comerciais por planta, em função das tensões avaliadas, podem ser explicadas pela regressão linear, a 1\% de probabilidade (Tabela $6)$.

Nota-se, pela Figura 8, que houve um acréscimo no número de frutos comerciais por planta, à medida que diminuíram as tensões de água no solo, dentro do intervalo estudado.

Observa-se que $97,50 \%$ das variações, ocorridas no número de frutos comerciais por planta, em função das tensões, são explicadas pela regressão linear inversa (Figura 8). 


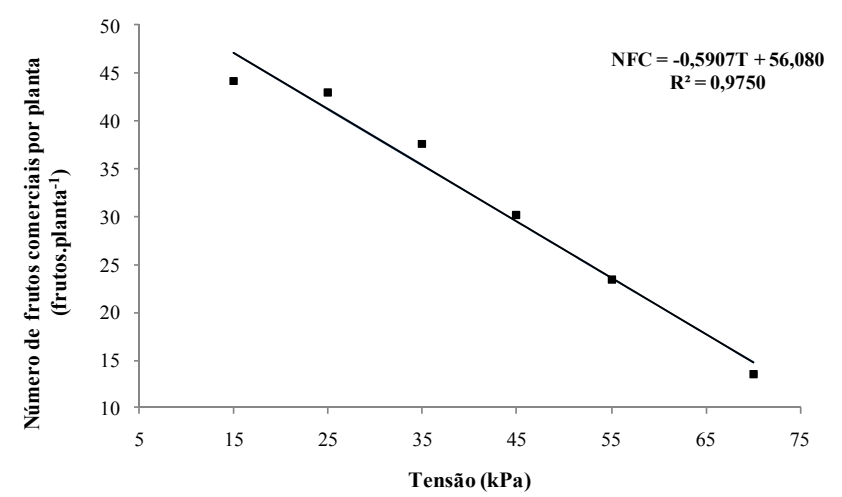

Figura 8. Número de frutos comerciais (NFC) por planta de morangueiro, em função das diferentes tensões de água no solo.

Oliveira e Scivittaro (2008), ao avaliar o desempenho produtivo de cultivares de morangueiro (Cegnidarem, Aromas e Diamante) nas condições climáticas do Rio Grande do Sul, e irrigadas por gotejamento, obtiveram 32,2 frutos comercias por planta para a cultivar Aromas. O resultado desses autores é muito próximo do valor médio encontrado no presente trabalho, que foi de 31,9 frutos comerciais por planta.

O maior valor encontrado para o número de frutos comerciais por planta no presente estudo foi de 47,22 frutos, obtidos à tensão de $15 \mathrm{kPa}$, com média geral de 31,96 frutos. Apresentando assim, valor maior em comparação ao experimento realizado no primeiro ciclo, cujo número de frutos comerciais por planta foi de 10,13 (COSTA, 2011).

De acordo com a análise de variância (Tabela 7), para massa média de frutos comerciais, verifica-se que não houve diferença significativa em relação ao fator tensão de água no solo. Vale relembrar que, os frutos comerciais analisados, são aqueles que possuem massa acima de $6 \mathrm{~g}$, assim as diferentes tensões estudadas não foram capazes de influenciar significativamente a característica de massa média.

Tabela 6. Resumo da análise de variância para massa média de frutos comerciais (MMFC), sob diferentes tensões de água no solo

\begin{tabular}{ccc}
\hline \multirow{2}{*}{ Fontes de variação } & \multirow{2}{*}{ G. L. } & Q. M. \\
\cline { 3 - 3 } & 2 & ${\text { MMFC }\left(\text { g.fruto }^{-1}\right)}^{\text {ns }}$ \\
Bloco & 5 & $2,17^{\mathrm{ns}}$ \\
Tensões & 10 & $3,30^{\mathrm{ns}}$ \\
Resíduo & - & 1,17 \\
\hline Média Geral & - & 10,98 \\
C.V. $(\%)$ & 9,83 \\
\hline
\end{tabular}

Nota: ${ }^{\text {ns }}$ - não significativo pelo teste F.

Assim sendo, os maiores valores de massa fresca comercial (produção comercial) que ocorreram à tensão de $15 \mathrm{kPa}$, é resultado do maior número de frutos produzidos, haja vista, que a massa média de frutos não foi influenciada significativamente pelas tensões avaliadas.

De acordo com a análise de variância (Tabela 8), verifica-se efeito significativo a 1\% de probabilidade, para a produtividade total de frutos, com relação ao fator tensões de água no solo. 
Tabela 7. Resumo das análises de variância e de regressão para produtividade total de frutos (PTF), sob diferentes tensões de água no solo

\begin{tabular}{ccc}
\hline \multirow{2}{*}{ Fontes de variação } & \multirow{2}{*}{ G. L. } & Q. M. \\
\cline { 3 - 3 } & 2 & PTF (t.ha \\
& Bloco & $154,00^{* * *}$ \\
Tensões & 5 & $412,17^{* *}$ \\
Resíduo & 10 & 13,76 \\
\hline Média Geral & - & 33,07 \\
C.V. $(\%)$ & - & 11,22 \\
\hline Linear & 1 & $2023,39^{* *}$ \\
Quadrática & 1 & $34,91^{\mathrm{ns}}$ \\
Desvios & 3 & $0,86^{\mathrm{ns}}$ \\
\hline Nota: $^{\text {ns }}$ - não significativo pelo teste F e ${ }^{* *}-$ significativo a $1 \%$ de probabilidade.
\end{tabular}

O resultado de produtividade total de frutos mostrou resposta linear inversa, com nível de significância de 1\% (Tabela 8), indicando haver um decréscimo da produtividade total de frutos à medida que se aumentaram as tensões de água no solo. Nota-se que $98,18 \%$ das variações ocorridas, na produtividade total de frutos, em função das tensões, são explicadas pela regressão linear inversa (Figura 9). O valor máximo para produtividade total de frutos ocorreu à tensão de $15 \mathrm{kPa}$, resultando em uma produtividade para esta característica de 47,99 t.ha ${ }^{-1}$.

De acordo com a equação representada na Figura 10, o aumento da tensão de água no solo, implicará em uma diminuição da produtividade total de frutos, considerando o intervalo estudado (15 a $70 \mathrm{kPa}$ ). Isto quer dizer que, quanto menor o intervalo entre irrigações (turno de rega), maior é a produtividade total de frutos, pois a água é aplicada em pequenas intensidades, porém, com alta frequência, de modo a manter a umidade do solo na zona radicular próxima à capacidade de campo.

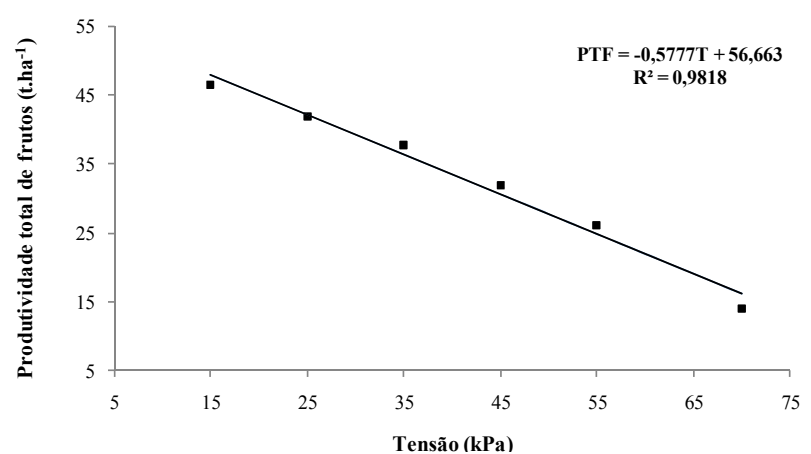

Figura 9. Produtividade total de frutos (PTF) de morangueiro, em função das diferentes tensões de água no solo.

De acordo com Taiz e Zeiger (2009), as plantas cultivadas em solo com água mais facilmente disponível apresentam maior desenvolvimento, área foliar e transpiração e consequentemente, exigem irrigações mais frequentes e maior volume de água para repor o que foi utilizado para o metabolismo, e também, "cedido" para a atmosfera.

Costa (2011) avaliando a produtividade do morangueiro das cultivares Oso grande e Aromas, sob o efeito de diferentes tensões de água no solo, na região sul de minas, com o transplantio realizado no mês de junho, obteve uma produtividade de 17,71 t.ha $^{-1}$ para a cultivar Aromas, comparado com o presente trabalho, houve um aumento de $260 \%$ o qual se 
deve, provavelmente, a época de início do estudo, mês de abril, e também ao rápido desenvolvimento das plantas devido à realização da poda drástica.

Pereira (2009), encontrou uma menor produtividade da cultivar Aromas quando o plantio foi realizado no mês de julho em comparação ao plantio no mês de maio.

De acordo com a análise de variância (Tabela 9), verifica-se efeito significativo a $1 \%$ de probabilidade, para produtividade comercial de frutos, com relação ao fator tensões de água no solo.

Tabela 8. Resumo das análises de variância e de regressão para produtividade comercial de frutos (PCF), sob diferentes tensões de água no solo.

\begin{tabular}{ccc}
\hline \multirow{2}{*}{ Fontes de variação } & G. L. & Q. M. \\
\cline { 3 - 3 } & 2 & PCF (t.ha \\
Bloco & 5 & $166,89^{* *}$ \\
Tensões & 10 & $447,61^{* *}$ \\
Resíduo & - & 13,79 \\
\hline Média Geral & - & 28,78 \\
C.V. (\%) & 1 & 12,91 \\
\hline Linear & 1 & $2209,78^{* *}$ \\
Quadrática & 3 & $20,66^{\mathrm{ns}}$ \\
Desvios & $2,54^{\mathrm{ns}}$ \\
\hline
\end{tabular}

Nota: ${ }^{\text {ns }}$ - não significativo pelo teste $\mathrm{F} \mathrm{e}^{\text {** }}$ - significativo a $1 \%$ de probabilidade.

No caso da produtividade comercial de frutos, as variações ocorridas podem ser explicadas pela regressão linear inversa, a 1\% de probabilidade (Tabela 9).

Nota-se, pela Figura 10, que houve um acréscimo na produtividade comercial de frutos, à medida que se diminuíram as tensões da água no solo. Observa-se que 98,74\% das variações, ocorridas na produtividade comercial de frutos, em função das tensões, são explicadas pela regressão linear.

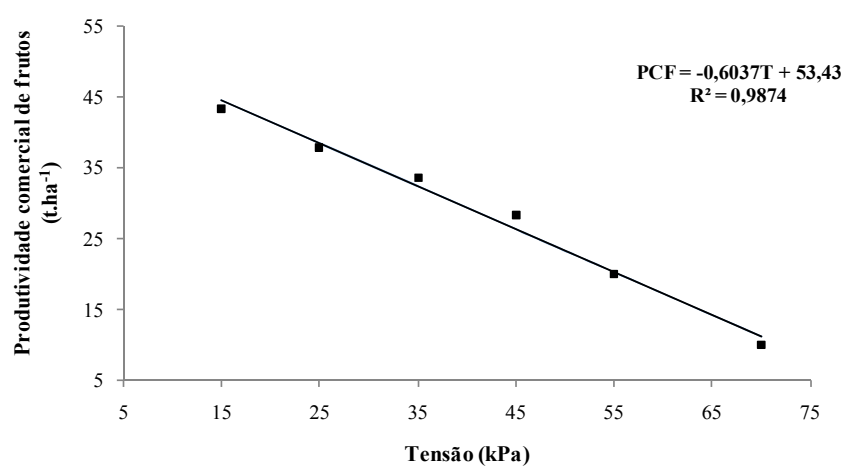

Figura 10. Produtividade comercial de frutos (PCF) de morangueiro, em função das diferentes tensões de água no solo.

$\mathrm{O}$ valor máximo para produtividade comercial de frutos ocorreu à tensão de $15 \mathrm{kPa}$, resultando em uma produtividade para este parâmetro de 44,37 t.ha ${ }^{-1}$.

Otto et al. (2009) avaliando a produção de frutos e a emissão de estolões das cultivares de dia neutro, incluindo a Aromas, durante o verão de Ponta Grossa, Paraná, em estufa do tipo arco, utilizando o sistema de gotejamento, obtiveram respostas de produtividade comercial média para a cultivar Aromas de 28,4 t.ha ${ }^{-1}$. Resultado este, próximo ao valor médio 
encontrado no presente experimento de $28,8 \mathrm{t}^{\mathrm{h}} \mathrm{ha}^{-1}$, entretanto, muito abaixo da produtividade máxima obtida na tensão de $15 \mathrm{kPa}$.

Segundo Pereira (2009), a cultivar Aromas apresenta melhor desempenho cultivada em maio, quando o fotoperíodo é curto e as temperaturas amenas.

\section{CONCLUSÕES}

Diante das condições em que o experimento foi desenvolvido e dos resultados obtidos para a cultura do morangueiro, pode-se concluir que:

1. Para a obtenção dos maiores valores de massa fresca total e comercial de frutos por planta, número total e comercial de frutos por planta e produtividade total e comercial, devese irrigar no momento em que a tensão de água no solo estiver em torno de $15 \mathrm{kPa}$, à profundidade de $0,15 \mathrm{~m}$;

2. A massa média de frutos comerciais e a massa fresca de frutos não comerciais por planta, não foram afetadas pelas diferentes tensões de água no solo avaliadas.

\section{REFERÊNCIAS BIBLIOGRÁFICAS}

CABELLO, F. P. Riegos localizados de alta frecuencia (RLAF) goteo, microaspersión, exudación. 3. ed. Madrid: Mundi-Prensa, 1996. 511 p.

CALVETE, E. O. et al. Produção hidropônica de morangueiro em sistema de colunas verticais, sob cultivo protegido. Revista Brasileira de Fruticultura, Jaboticabal, v. 29, n. 3, p. 501-506, 2007.

CARVALHO, L. G.; SAMPAIO, S. C.; SILVA, A. M. Determinação da umidade na capacidade de campo in situ de um Latossolo Roxo Distrófico. Engenharia Rural, Piracicaba, v. 7, n. 1, p. 1-97, dez. 1996.

CARVALHO, S. P. Histórico, importância socioeconômica e zoneamento da produção de morango no estado de Minas Gerais. In: . (Coord.). Boletim do morango: cultivo convencional, segurança alimentar, cultivo orgânico. Belo Horizonte: FAEMG, 2006. p. 9-13.

COSTA, G. G. Produção e qualidade de frutos do morangueiro, sob diferentes tensões de água no solo. 2011. 76 p. Dissertação ( Mestrado em Engenharia Agrícola) - Universidade Federal de Lavras, Lavras, 2011.

DANTAS, A. A. A.; CARVALHO, L. G.; FERREIRA, E. Classificação e tendências climáticas em Lavras, MG. Ciência e Agrotecnologia, Lavras, v. 31, n. 6, p. 1862-1866, nov./dez. 2007.

DIAS, M. S. C. et al. Morango. In: DE PAULA JÚNIOR, T. J.; VENZON, M. (Coord.). 101 culturas: manual de tecnologias agrícolas. Belo Horizonte: EPAMIG, 2007. p. 569-580. 
DOURADO NETO, D. et al. Programa para confecção da curva de retenção de água no solo utilizando o modelo de van Genuchten. Engenharia Rural, Piracicaba, v. 1, p. 92-102, jul. 1990.

DUARTE FILHO, J.; ANTUNES, L. E. C.; PÁDUA, J. G. Cultivares. Informe Agropecuário, Belo Horizonte, v. 28, n. 236, p. 20-23, jan./fev. 2007.

EL-FARHAN, A. H.; PRITTS, M. Water requirements and water stress in strawberry. The New York Berry News, Ithaca, v. 1, n. 1, p. 5-7, mar. 2002.

EMPRESA BRASILEIRA DE PESQUISA AGROPECUÁRIA. Centro Nacional de Pesquisa de Solos. Sistema brasileiro de classificação de solos. Rio de Janeiro: EMBRAPA Solos, 1999. $412 \mathrm{p}$.

FERREIRA, D. F. Análises estatísticas por meio do Sisvar para Windows: versão 4.0. In: REUNIÃO ANUAL DA REGIÃO BRASILEIRA DA SOCIEDADE INTERNACIONAL DE BIOMETRIA, 45., 2000, São Carlos. Anais... São Carlos: Sociedade Internacional de Biometria, 2000. p. 255-258.

GOMES, F. P. Curso de estatística experimental. 14. ed. Piracicaba: ESALQ/ USP, 2000. $477 \mathrm{p}$.

GOMES, L. A. A.; SILVA, E. C.; FAQUIN, V. Recomendações de adubação para cultivos em ambiente protegido. In: RIBEIRO, A. C.; GUIMARÃES, P. T. G.; ALVAREZ, V. H. (Ed.). Recomendações para o uso de corretivos e fertilizantes em Minas Gerais (5 $\mathbf{5}^{\mathbf{a}}$ aproximação). Viçosa, MG: UFV, 1999.

OLIVEIRA, R. P.; SCIVITTARO, W. B. Cegnidarem: nova cultivar de morangueiro recomendada para o Rio Grande do Sul. Pelotas: Embrapa, 2008. (Comunicado Técnico, 180). Disponível em: $<$ http://www.cpact.embrapa.br/publicacoes/download/comunicados/ comunicado_180.pdf $>$. Acesso em: 25 jun. 2011.

OTTO, R. F. et al. Cultivares de morango de dia neutro: produção em função de doses de nitrogênio durante o verão. Horticultura Brasileira, Brasília, v. 27, p. 99-110, 2009.

PACHECO, D. D. et al. Nutrição mineral e adubação do morangueiro. Informe Agropecuário, Belo Horizonte, v. 28, n. 236, p. 40-49, jan./fev. 2007.

PEREIRA, W. R. Produtividade e qualidade de frutos de cultivares de morangueiro, em diferentes épocas de plantio. 2009. 46 p. Tese (Doutorado em Produção Vegetal) Universidade Federal de Lavras, Lavras, 2009.

PIRES, R. C. M. et al. Produção do morangueiro em diferentes níveis de água, coberturas do solo e ambientes de cultivo. Irriga, Botucatu, v. 12, n. 3, p. 338-353, jul./set. 2007.

SANHUEZA, R. M. V. et al. Importância da cultura. In: Sistema de Produção de morango para mesa na Região da Serra Gaúcha e Encosta Superior do Nordeste. Bento Gonçalves: Embrapa Uva e Vinho, 2005. (Documento, 6). 
SERRANO, L. et al. Effects of irrigation regimes on the yield and water use of strawberry. Irrigation Science, Heidelberg, v. 13, p. 45-48, 1992.

TAIZ, L; ZEIGER, E. Fisiologia vegetal. 4. ed. Porto Alegre: Artmed, 2009. 819 p.

VAN GENUCHTEN, M. A closed-form equation for predicting the hydraulic conductivity of unsaturated soils. Soil Science Society American Journal, Madison, v. 44, n. 5, p. 892-898, Sept./Oct. 1980. 